\title{
Application of Corncob Residue-derived Catalyst in the Transesterification of Glycerol with Dimethyl Carbonate to Synthesize Glycerol Carbonate
}

\begin{abstract}
Song Wang, ${ }^{\mathrm{a}, *}$ Jianye Wang, ${ }^{\mathrm{a}}$ Patrick U. Okoye, ${ }^{\mathrm{b}}$ Shuang Chen, ${ }^{\mathrm{a}} \mathrm{Xinshu} \mathrm{Li},{ }^{\mathrm{a}}$ Lin Duan, ${ }^{\mathrm{a}}$ Huan Zhou, ${ }^{\text {a }}$ Sanxi Li, ${ }^{\text {a }}$ Tao Tang, ${ }^{\mathrm{c}}$ Linnan Zhang, ${ }^{\mathrm{a}}$ and Ailing Zhang ${ }^{\mathrm{a}}$

Corncob was calcined within a temperature range of $300{ }^{\circ} \mathrm{C}$ to $700{ }^{\circ} \mathrm{C}$ to prepare a series of corncob residue catalysts for the transesterification of glycerol with dimethyl carbonate (DMC) to synthesize glycerol carbonate (GC). Among the catalysts, the corncob residue catalyst obtained through calcination of corncob at $500{ }^{\circ} \mathrm{C}$ (CCR-500) showed a relatively high basicity and satisfactory catalytic activity. The structural investigation results indicated that CCR-500 was composed of carbon material and some alkaline mineral salts. Using CCR-500 as the catalyst, a glycerol conversion of $98.1 \%$ and a GC yield of $94.1 \%$ were achieved when the reaction was performed at $80^{\circ} \mathrm{C}$ for $90 \mathrm{~min}$, with a catalyst amount of 3 wt\% and glycerol to DMC molar ratio of 1:3. The comparison of CCR-500 with the reported catalysts indicated that the CCR-500 was a low-cost, high-active, and easily-accessible catalyst for the transesterification of glycerol with DMC.
\end{abstract}

Keywords: Glycerol; Corncob; Catalyst; Glycerol carbonate; Transesterification

Contact information: a: School of Science, Shenyang University of Technology, Shenyang, 110870, China b: Laboratorio de Bioenergía, Instituto de Energías Renovables (IER-UNAM), Temixco Morelos, 62580, México; c: State Key Laboratory of Polymer Physics and Chemistry, Changchun Institute of Applied Chemistry, Chinese Academy of Sciences, Changchun, 130022, China;

*Corresponding author: wangsong@ @ut.edu.cn

\section{INTRODUCTION}

The biodiesel industry has rapidly developed in the past decade because biodiesel shows great advantages, with respect to biodegradability and non-toxicity, compared with traditional fossil fuels (Sani et al. 2015). However, the preparation process of biodiesel can generate glycerol as a by-product. Generally, when $10 \mathrm{~kg}$ of biodiesel is produced, about 1 $\mathrm{kg}$ of glycerol can be simultaneously generated as a by-product. It was reported that the production of biodiesel has already exceeded 10 million tons every year in Europe, which means that roughly 1 million tons glycerol has been generated annually (Algoufi and Hameed 2014). Such a large amount of glycerol has forced biodiesel enterprises to pay extra costs to store and handle the generated glycerol, which consequently can hinder the development of the biodiesel industry. To change this situation, it is necessary to find effective ways to manage the oversupplied by-product, glycerol. Therefore, investigations on glycerol-based high-value-added chemicals have drawn much attention in recent years, and a series of valuable chemicals have been developed.

Glycerol carbonate (GC) is a typical glycerol based high-value-added chemical. Its advantages, which include biodegradability, high boiling point, low volatility, non-toxicity, and good reaction activity, have made it an attractive chemical for industrial applications 
(Wang et al. 2017). Glycerol carbonate can be synthesized by the transesterification of glycerol with dimethyl carbonate (DMC). This method has many advantages, such as mild reaction conditions, high GC yield, and an environment-friendly preparation process, compared with other GC synthesis methods (Nguyen-Phu et al. 2018). When using this method to synthesize GC, a base catalyst must be used. Homogeneous catalysts, such as potassium hydroxide and sodium hydroxide, exhibit high reaction activity. However, homogeneous catalysts cannot be reused, which is unfavorable for industrial applications. Thus, various heterogeneous catalysts have been developed, including alkaline metal oxide or mixed metal oxide (Algoufi et al. 2017), alkaline phosphate (Okoye et al. 2016), alkaline silicate (Wang et al. 2018), and ionic liquid (Chen et al. 2015). Despite the high catalytic activity, these catalysts have exhibited some problems including preparation costs or complex preparation procedures. Developing low-cost and high-active base catalysts has become an important aspect in the field of the transesterification of glycerol with DMC. Given the negligible cost of the feedstock, the direct use of waste materials rather than chemical reagents to prepare the base catalyst in transesterification reactions has drawn increased attention. Some waste materials have been used as the feedstock for preparing base catalysts, including eggshell (Gupta et al. 2018), chicken manure (Jung et al. 2017), fish waste (Shikhaliyev et al. 2018), marine barnacle (Manaf et al. 2018), disposable diapers (Wang et al. 2019), and oil palm empty fruit bunch (Okoye et al. 2019). Therefore, utilizing waste materials to prepare a base catalyst can allow for new ways to synthesize GC using the transesterification of glycerol with DMC.

Corn is an important crop across the globe. In 2016, global corn production reached over 1 billion tons. Processing corn can generate a significant amount of corncob, which can account for approximately $17 \%$ of the total weight of the overall corn production (Li et al. 2018a). In some developing countries, corncob is directly discarded as waste or burned in farmland, which causes serious environmental issues and endangers public health. To solve this problem, investigations on how to efficiently utilize corncob have been researched. There are mainly three ways to realize the high-efficient utilization of corncob. The first is through biotechnological treatment, through which corncob can be used as feedstock to prepare bioethanol (Kleingesinds et al. 2018), lignin (You et al. 2019), and fumaric acid (Li et al. 2018b). The second is through pyrolysis treatment. By controlling the conditions of pyrolysis, high quality bio-oil and carbon materials can be obtained. The bio-oil obtained from pyrolysis treatment contains substantial high-value-added chemicals such as guaiacol, 2-methoxy-4-vinylphenol, and 4-vinylphenol (Demiral et al. 2012). Moreover, the carbon materials obtained from pyrolysis treatment can be used as the electrode for a supercapacitor (Qu et al. 2015) and high-performance adsorbents (Farnane et al. 2018). The third is through a burning process. Because the energy content of corncob is approximately $19 \mathrm{MJ} / \mathrm{kg}$, which is significantly higher than that of grass or wood, corncob can be directly used as the solid biomass fuel in industries for power production or heat generation (Ioannidou et al. 2009). However, most of the generated corncob ash is disposed of in landfill sites, which causes such problems as occupation of the land and leachate pollution to underground water bodies. Therefore, the potential of utilizing corncob in industrial applications must be further explored, which can benefit both corncob waste management and environmental protection.

To expand the application field of corncob waste and promote the conversion of the oversupplied glycerol to valuable GC, a series of corncob residue catalysts were prepared and applied in the transesterification of glycerol with DMC for the first time. The effect of the preparation conditions on the catalytic activity of the corncob residue catalysts was investigated. 
The properties of the corncob residue catalyst, which showed satisfactory catalytic activity, were characterized using thermogravimetric analysis (TGA), field emission scanning electron microscopy (FESEM), energy-dispersive X-ray spectroscopy (EDX), Brunauer-Emmet-Teller (BET) surface area analysis, Fourier transform infrared spectroscopy (FTIR), X-ray diffraction (XRD) analysis, and the titration method. After investigating the effect of the reaction conditions on the catalytic activity of this corncob residue catalyst, its performance was compared with that of the reported catalysts.

\section{EXPERIMENTAL}

\section{Materials}

The corncob used in the present study was collected from Fushun County, Liaoning, China. All chemical reagents, including glycerol, DMC, and ethanol, were obtained from Damao Chemical Reagent Co., Ltd., Tianjin, China. These analytical grade reagents were used directly without further purification.

\section{Methods}

Preparation of the catalyst

The preparation procedure of the catalyst was similar to the literature (Gohain et al. 2017). The corncob was washed three times with twice-distilled water to remove the dust on its surface. Then, the cleaned corncob was oven-dried at $110^{\circ} \mathrm{C}$ for $48 \mathrm{~h}$. After that, the dried corncob was ground into particles using a grinder (SA-20; Jitian Plastic Machinery Co., Ltd., Dongguan, China). The corncob particles were calcined in air using a muffle furnace at the selected temperature ranging from $300{ }^{\circ} \mathrm{C}$ to $700{ }^{\circ} \mathrm{C}$ for $4 \mathrm{~h}$. Then the residue was triturated and passed through a 180 mesh sieve. The obtained corncob residue powder was collected and applied in the transesterification of glycerol with DMC. The corncob residue catalyst was named as CCR-T, where CCR means corncob residue and $\mathrm{T}$ indicates the calcination temperature. For example, the catalyst prepared by calcination of the corncob at $500{ }^{\circ} \mathrm{C}$ for $4 \mathrm{~h}$ was named CCR-500.

\section{Characterization of the catalyst}

The thermal decomposition behavior of the corncob was examined using a thermogravimetric analyzer (Q50; TA Instruments, New Castle, DE, USA) from room temperature to $800{ }^{\circ} \mathrm{C}$ under air flow. The functional group of the corncob residue was investigated with a Fourier transform infrared spectrometer (Prestige-21; Shimadzu Corporation, Kyoto, Japan). The morphology and elemental composition of the corncob residue catalyst was examined using a field emission scanning electron microscope fitted with an energy-dispersive X-ray spectrometer (SU8010N; Hitachi Limited, Tokyo, Japan). The XRD pattern of the catalyst was recorded via a powder X-ray diffractometer (XRD6000; Shimadzu Corporation, Kyoto, Japan) using CuK $\alpha$ radiation at $40 \mathrm{kV}$ and $30 \mathrm{~mA}$ with a scanning speed of $5^{\circ} \mathrm{min}^{-1}$. The Brunauer-Emmet-Teller surface area was determined via nitrogen adsorption/desorption isotherms using a volumetric adsorption instrument (JWBK122W; JWGB Sci. Tech. Co., Ltd., Beijing, China). The total basicity of the catalyst was determined by the acid-base titration method used in previous studies (Chakraborty et al. 2010). 
Transesterification of glycerol with DMC

To complete the transesterification reaction of glycerol with DMC, a 100-mL threenecked flask reactor attached with a magnetic stirrer, a thermometer, and a reflux condenser was used. In a typical experiment, $4.6 \mathrm{~g}$ of glycerol and $13.5 \mathrm{~g}$ of DMC (molar ratio glycerol: DMC of 1:3) were mixed in the three-necked flask reactor at the agitation speed of $500 \mathrm{rpm}$. A certain amount of corncob residue (e.g., $0.54 \mathrm{~g}, 3 \mathrm{wt} \%$ of raw material) was added into the three-necked flask reactor to start the reaction when the mixture of the reactants was heated to the pre-set temperature $\left(e . g ., 80^{\circ} \mathrm{C}\right)$. The transesterification reaction of glycerol with DMC was conducted at this temperature for a specific time (e.g., $90 \mathrm{~min})$. After the reaction, the catalyst was removed from the reaction mixture via filtration. The composition of the reaction product was analyzed using a gas chromatograph (Agilent GC-7890A; Agilent Technologies, Santa Clara, CA, USA), which was fitted with a flame ionization detector. Based on the results of the composition of the reaction product, the glycerol conversion and GC yield were quantitatively calculated using the method reported in a literature (Shikhaliyev et al. 2018).

\section{RESULTS AND DISCUSSION}

\section{Thermal Decomposition Behavior of Corncob}

The thermal decomposition behavior of the corncob is presented in Fig. 1. The weight loss of the corncob during the heating process can be divided into three stages. The first stage occurred at the temperature below $150{ }^{\circ} \mathrm{C}$. In this stage, a slight weight loss of approximately $3 \%$ was observed, which was attributed to the evaporation of the physically absorbed moisture.

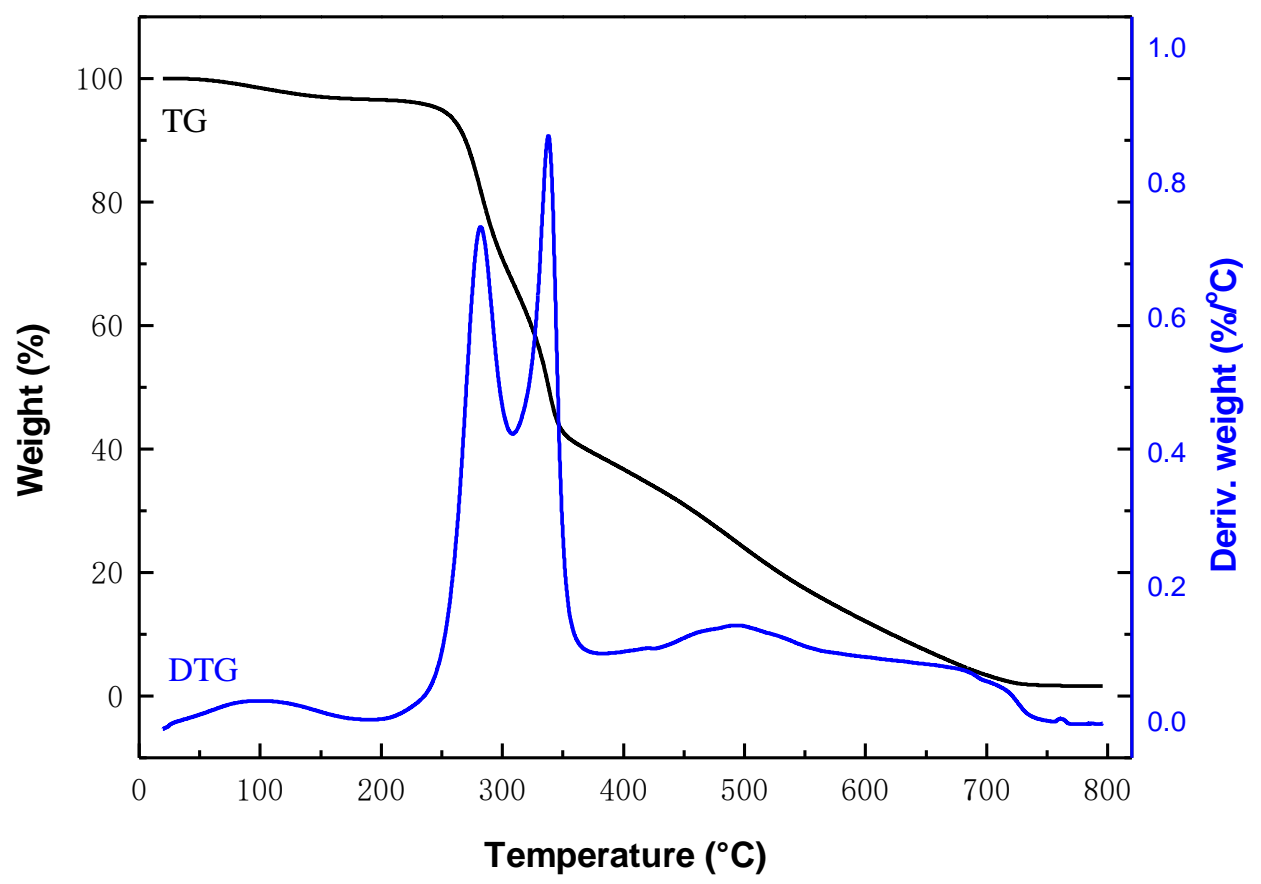

Fig. 1. Thermogravimetric analysis (TGA) and derivation thermogram (DTG) curves of the corncob 
The second stage occurred in the temperature range of $250{ }^{\circ} \mathrm{C}$ to $350{ }^{\circ} \mathrm{C}$. A rapid weight loss of approximately $57 \%$ was observed when the temperature increased from 250 ${ }^{\circ} \mathrm{C}$ to $350{ }^{\circ} \mathrm{C}$. Moreover, two distinct peaks appeared in the corresponding DTG curve. The first peak corresponded to the decomposition of hemicellulose in the corncob and the second peak was due to the decomposition of cellulose in the corncob (Zhang et al. 2018a). The third stage happened in the temperature range $350{ }^{\circ} \mathrm{C}$ to $725{ }^{\circ} \mathrm{C}$. In this stage, the rate of weight loss was slow with a weight loss of approximately $38 \%$, which was caused by the decomposition of the lignin in the corncob and the carbon material formed during the heating process (Gupta et al. 2018). When the temperature was higher than $725^{\circ} \mathrm{C}$, no obvious weight loss was observed. Because most of the organic materials and carbon material decomposed during the heating process, the corncob residue remaining at above $725^{\circ} \mathrm{C}$ was mainly composed of inorganic salts and oxides. The TGA results showed the complex thermal decomposition behavior of the corncob. When the corncob was calcined at different temperatures, the composition of its corresponding residue was different, leading to different catalytic activity in the corncob residue catalysts. Thus, it was necessary to first investigate the catalytic activity of the corncob residue catalysts obtained after the calcination of the corncob at different temperatures.

\section{Effect of the Calcination Temperature on the Catalytic Activity of the Corncob Residue Catalysts}

Corncob showed no catalytic ability, while the corncob residues that were calcined at different temperatures exhibited different catalytic abilities. Figure 2 shows that the glycerol conversion increased from $1.9 \%$ to $98.1 \%$ when the calcination temperature was increased from $300{ }^{\circ} \mathrm{C}$ to $500{ }^{\circ} \mathrm{C}$. With a further increase in the calcination temperature, a slight change of the glycerol conversion appeared. Usually, the catalytic activity of a catalyst used in the transesterification reaction strongly depends on its total basicity (Wang et al. 2017). Thus, the corresponding total basicity of the prepared catalysts was determined, and the results are presented in Fig. 2. Compared with the effect of the calcination temperature on the glycerol conversion, the effect of the calcination temperature on the total basicity exhibited a similar tendency. When the corncob was calcined at $300{ }^{\circ} \mathrm{C}$ for $4 \mathrm{~h}$, the lowest total basicity of $0.3 \mathrm{mmol} / \mathrm{g}$ was obtained. When the calcination temperature was increased to $500{ }^{\circ} \mathrm{C}$, the total basicity of the prepared CCR-500 rose rapidly to $8.8 \mathrm{mmol} / \mathrm{g}$. This occurred because the higher total basicity resulted in relatively higher glycerol conversion (Okoye et al. 2019). The glycerol conversion reached 98.1\% when the CCR-500 was used as the catalyst in the transesterification reaction. A further increase of the calcination temperature to $600{ }^{\circ} \mathrm{C}$ and $700{ }^{\circ} \mathrm{C}$ did not lead to a rapid increase of the total basicity of the CCR-600 (9.3 mmol/g) and CCR-700 (9.7 mmol/g), which showed similar catalytic activity to the CCR-500. These investigation results demonstrated that during the calcination process, the content of the alkaline substance in the corncob residue catalysts rose with the increased calcination temperature. The increase of the content of the alkaline substance led to higher total basicity and catalytic activity of the CCR-500, CCR-600, and CCR-700 than was recorded for the CCR-300 and CCR-400. Considering its relatively high catalytic activity and low preparation temperature, the CCR-500 was selected as the optimum catalyst for further investigations. Because the study on the total basicity of the catalysts could not provide more information on the structure and component of the catalyst, the FESEM, BET, FTIR, EDX, and XRD investigations on the CCR-500 were performed. 


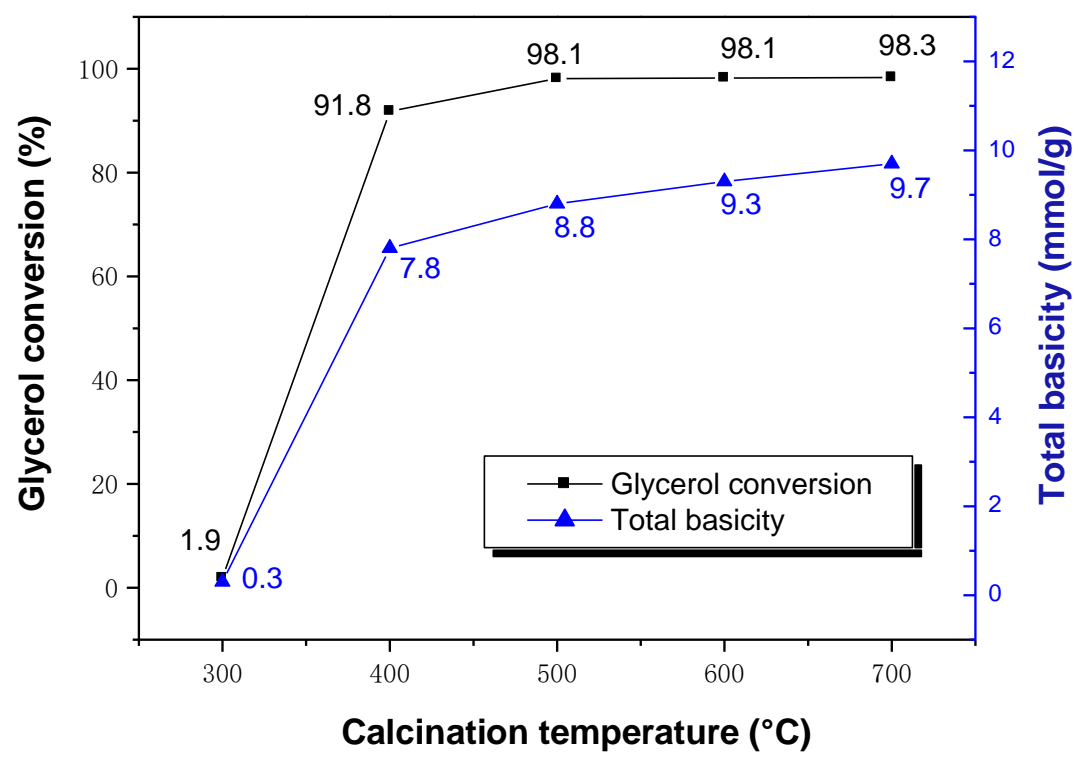

Fig. 2. Effect of the calcination temperature on the catalytic activity and total basicity of the corncob residue catalysts; reaction conditions: glycerol: $0.05 \mathrm{~mol}(4.6 \mathrm{~g})$, DMC: $0.15 \mathrm{~mol}(13.5 \mathrm{~g})$, catalyst amount: $3 \mathrm{wt} \%(0.54 \mathrm{~g})$, temperature: $80^{\circ} \mathrm{C}$, and time: $90 \mathrm{~min}$

\section{Characterization of Corncob and the CCR-500}

The FESEM surface images of the corncob and the CCR-500 are shown in Fig. 3. The surface morphology of the corncob and the CCR-500 was considerably different. Figure 3 a shows a representative cavity structure with a diameter higher than $10 \mu \mathrm{m}$ that was observed on the surface of the corncob (Guo et al. 2017). However, this kind of cavity cannot be found on the surface of CCR-500, which presented an irregular morphology with the particles, bulges, and cracks aggregated sporadically on its surface. The FESEM investigation demonstrated that thermal decomposition of the corncob occurred during the calcination process, leading to different surface morphologies for the corncob and the CCR500. Moreover, the BET surface area of the CCR-500 $\left(3.08 \mathrm{~m}^{2} \mathrm{~g}^{-1}\right)$ was higher than that of the corncob $\left(2.54 \mathrm{~m}^{2} \mathrm{~g}^{-1}\right)$ (Table S1), while the pore diameter of the CCR-500 was smaller than that of the corncob, indicating that with the change in the surface morphology of the CCR-500, the textural properties of the CCR-500 changed correspondingly.
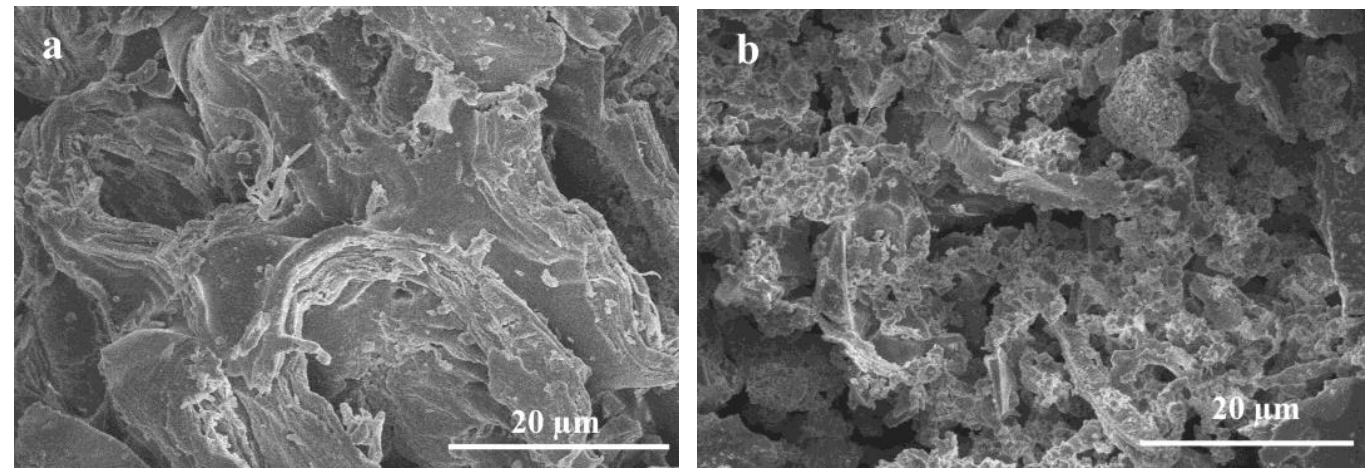

Fig. 3. FESEM surface images of (a) corncob and (b) CCR-500 
Figure 4 shows the FTIR spectra of the corncob and CCR-500 in the range of 4000 $\mathrm{cm}^{-1}$ to $400 \mathrm{~cm}^{-1}$. As can be observed from the spectrum of the corncob, a strong and broad peak appeared at above $3000 \mathrm{~cm}^{-1}$, which can be associated with the stretching vibration of $\mathrm{O}-\mathrm{H}$ and N-H (Farnane et al. 2018). The peak at $2931 \mathrm{~cm}^{-1}$ was ascribed to the C-H stretching vibration of cellulose and hemicellulose in corncob. The peak at $1730 \mathrm{~cm}^{-1}$ was the typical stretching vibration of the xylan component in hemicellulose (Chen et al. 2018). The presence of the peak at $1515 \mathrm{~cm}^{-1}$ came from the benzene skeletal vibration of lignin. The peaks at $1259 \mathrm{~cm}^{-1}, 1121 \mathrm{~cm}^{-1}$, and $1149 \mathrm{~cm}^{-1}$ can be assigned to the stretching vibrations of C-O-C, C-O, and C-OH, respectively (Zhu et al. 2018). The weak peak at $899 \mathrm{~cm}^{-1}$ was due to the presence of the $\beta$-(1-4)-glycosidic linkage (Zheng et al. 2019). These observed peaks from the spectrum of the corncob were all characteristic vibrations of the cellulose, hemicelluloses, and lignin in the corncob. However, most of these peaks, including the peaks at $2931 \mathrm{~cm}^{-1}, 1730 \mathrm{~cm}^{-1}, 1515 \mathrm{~cm}^{-1}, 1259 \mathrm{~cm}^{-1}, 1049 \mathrm{~cm}^{-1}$, and $899 \mathrm{~cm}^{-1}$, were not observed in the CCR-500 spectrum, which suggested that the organic component in the corncob decomposed. Moreover, some new peaks appeared in the CCR-500 spectrum. The peaks at $881 \mathrm{~cm}^{-1}$ and $699 \mathrm{~cm}^{-1}$ came from the vibration of carbonate (Wang et al. 2019). The peak at $1061 \mathrm{~cm}^{-1}$ can be ascribed to phosphate (Shikhaliyev et al. 2018). The peaks at around 1468 $\mathrm{cm}^{-1}$ and $1452 \mathrm{~cm}^{-1}$ can be related to the vibration of chloride and silicate, respectively (Indran et al. 2016). The FTIR investigations indicated that with the decomposition of the organic materials, mineral salts formed in the corncob residue during the calcination process of the corncob.

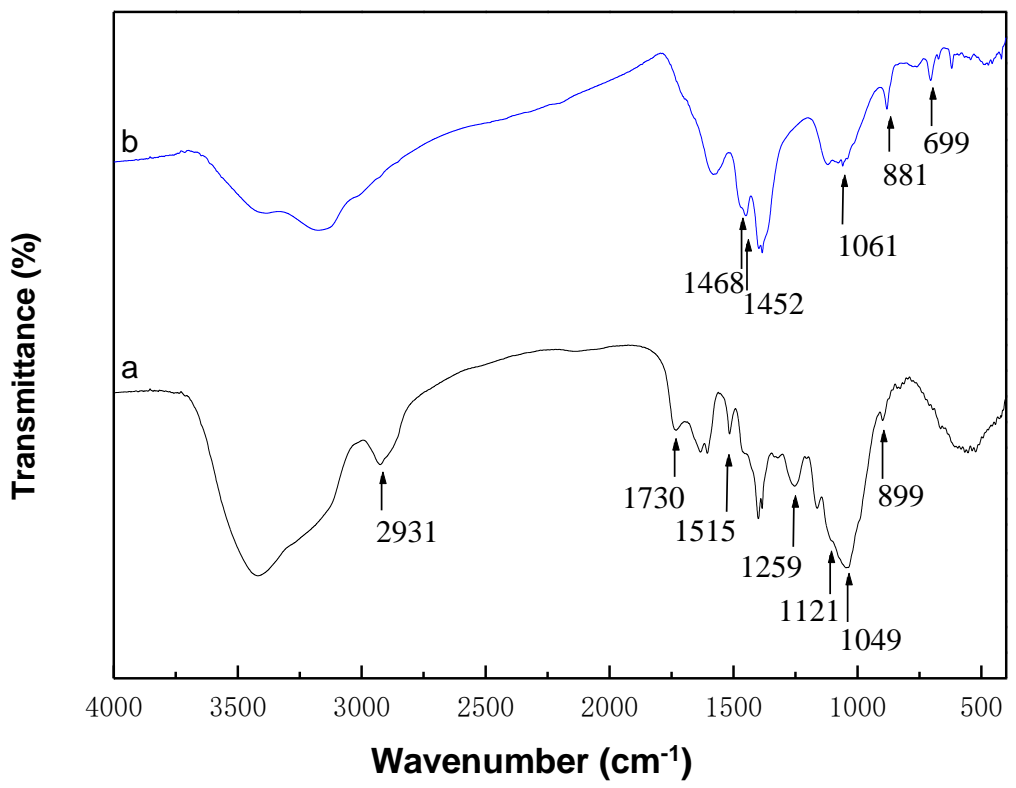

Fig. 4. FTIR spectra of (a) corncob and (b) the CCR-500

Figure 5 presents the XRD investigation results of the corncob and the CCR-500. Two broad diffraction peaks were observed at approximately $16.6^{\circ}$ and $21.6^{\circ}$ in the XRD pattern of the corncob. These two peaks indicated the presence of the crystalline cellulose in the corncob (Kleingesinds et al. 2018). After the calcination of the corncob at $500{ }^{\circ} \mathrm{C}$, due to the decomposition of cellulose, the diffraction peaks of cellulose disappeared, and some sharp diffraction peaks appeared in the XRD pattern of the CCR-500. The strong characteristic peaks of potassium chloride can be observed at $28.3^{\circ}, 40.5^{\circ}, 50.1^{\circ}$, and $66.4^{\circ}$ 
(Joint Committee on Powder Diffraction Standards (JCPDS) No. 41-1476). The peaks that appeared at $26.1^{\circ}, 31.6^{\circ}, 34.1^{\circ}, 37.7^{\circ}, 42.8^{\circ}$, and $45.5^{\circ}$ were attributed to the diffraction peaks of potassium carbonate (JCPDS No.16-0820). Despite these characteristics of the diffraction peaks of potassium chloride and potassium carbonate, some weak diffraction peaks of other mineral salts were also observed in Fig. 5b. The peak that appeared at $30.9^{\circ}$ was attributed to the diffraction peak of potassium aluminum pyrophosphate (JCPDS No. 36-1459). The peak corresponding to potassium silicate was observed at $29.6^{\circ}$ (JCPDS No.49-0163). The peak that appeared at $27.9^{\circ}$ was attributed to the diffraction peak of potassium magnesium phosphate (JCPDS No. 50-0146). These XRD investigations revealed the complex composition of CCR-500, which included halide, carbonate, silicate, and phosphate. As reported in literatures, these alkaline mineral salts, including potassium carbonate, potassium silicate, led to the high catalytic performance of CCR-500 ( Li et al. 2013; Indran et al. 2016). Meanwhile, both Fig. 1 and Fig. 4 show that the corncob was not totally decomposed at $500{ }^{\circ} \mathrm{C}$, and that carbon material was still present in the CCR-500. These investigations demonstrated that CCR-500 is a composite of carbon material and alkaline mineral salts. The remaining carbon material, which has high stabilizing ability on the mineral salts (Li et al. 2013), can stabilize these alkaline mineral salts to make the CCR500 a high-performance heterogeneous catalyst.

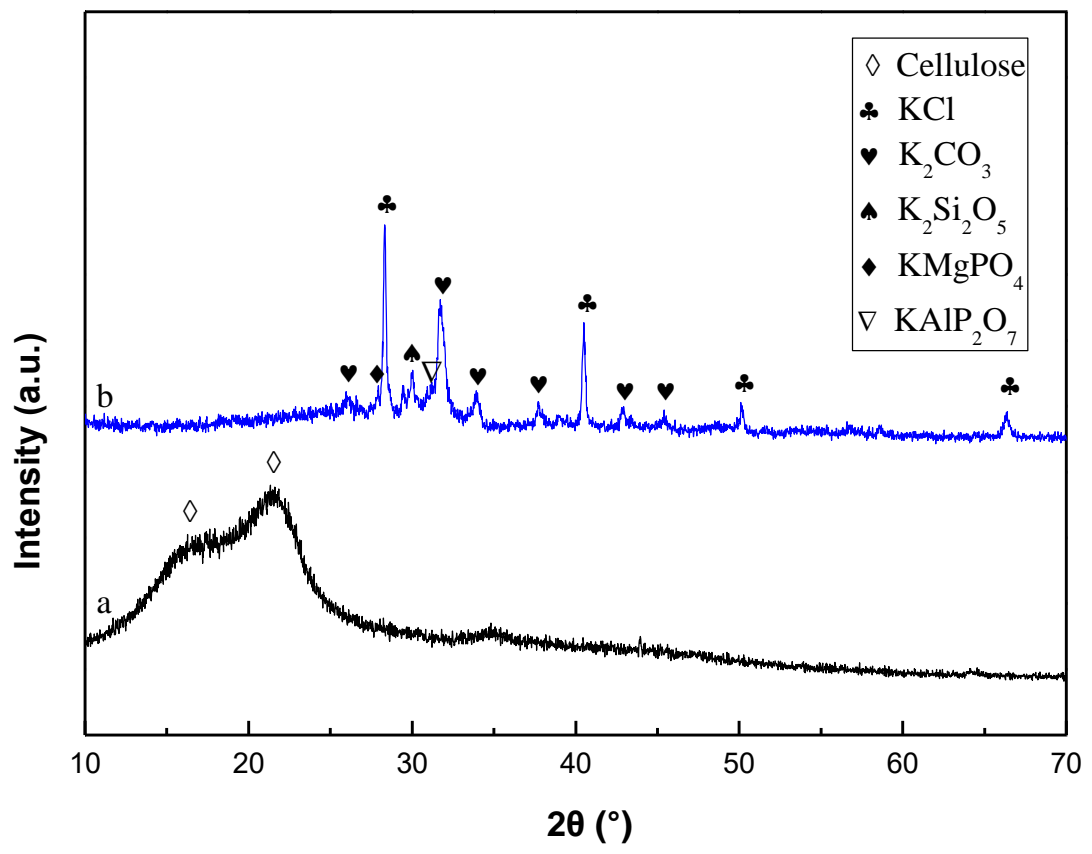

Fig. 5. XRD patterns of (a) corncob and (b) CCR-500

\section{Catalytic Performance of the CCR-500}

Effect of the reaction parameters on the transesterification reaction

Figure 6a presents the effect of the molar ratio of glycerol to DMC on the transesterification reaction of glycerol with DMC. As the molar ratio of glycerol to DMC was varied from 1:1 to 1:3, the glycerol conversion and GC yield constantly increased. The high glycerol conversion of $98.1 \%$ and GC yield of $94.1 \%$ were achieved when the molar ratio of glycerol to DMC reached 1:3. A further increase of the portion of DMC did not lead to any obvious increase of the glycerol conversion and GC yield. Meanwhile, greater use of 
DMC corresponded with higher costs for purification of the product by distillation. As such, the suitable molar ratio of glycerol to DMC was 1:3.
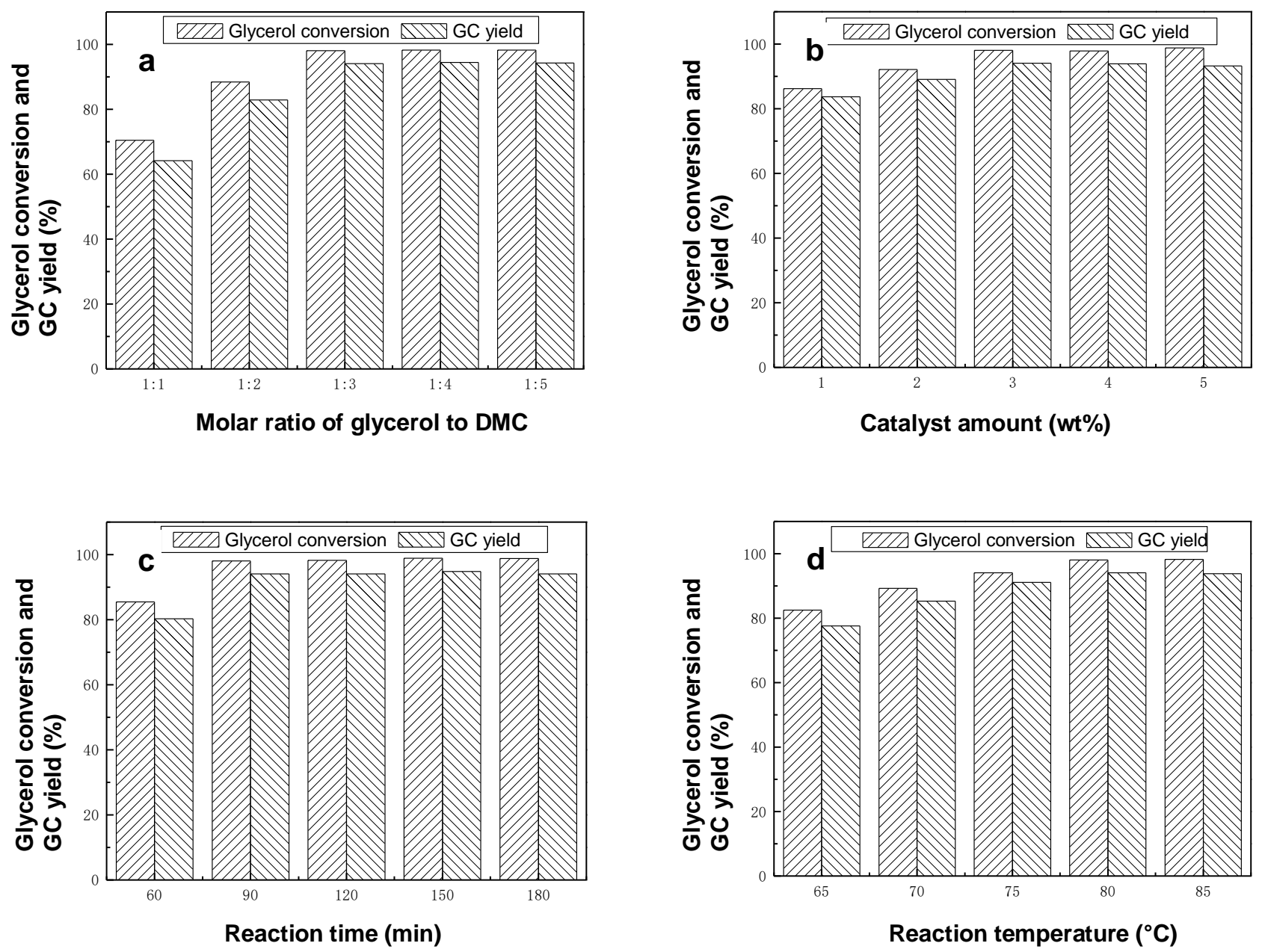

Fig. 6. (a): The effect of the molar ratio of glycerol to DMC (reaction conditions: catalyst amount: 3 wt\% $(0.54 \mathrm{~g})$, temperature: $80^{\circ} \mathrm{C}$, time: $\left.90 \mathrm{~min}\right)$; (b): Effect of the catalyst amount (reaction conditions: glycerol: $0.05 \mathrm{~mol}(4.6 \mathrm{~g})$, DMC: $0.15 \mathrm{~mol}(13.5 \mathrm{~g})$, temperature: $80^{\circ} \mathrm{C}$, time: $\left.90 \mathrm{~min}\right)$; (c): Effect of the reaction time (reaction conditions: glycerol: $0.05 \mathrm{~mol}(4.6 \mathrm{~g}), \mathrm{DMC}: 0.15 \mathrm{~mol}$ (13.5 g), catalyst amount: $3 \mathrm{wt} \%(0.54 \mathrm{~g})$, temperature: $80^{\circ} \mathrm{C}$; (d): Effect of the reaction temperature (reaction conditions: glycerol: $0.05 \mathrm{~mol}(4.6 \mathrm{~g})$, DMC: $0.15 \mathrm{~mol}(13.5 \mathrm{~g})$, catalyst amount: $3 \mathrm{wt} \%$ (0.54 g), time: $90 \mathrm{~min}$

The effect of the catalyst amount on the transesterification reaction of glycerol with DMC is shown in Fig. 6b. When the catalyst amount was increased from $1 \%$ to $3 \%$, the glycerol conversion and GC yield rose from $86.2 \%$ to $98.1 \%$ and $83.7 \%$ and $94.1 \%$, respectively. This was due to the fact that the active alkaline site in the reaction mixture increased with the increase of the catalyst amount. With a further increase of the catalyst amount, the glycerol conversion rose slightly, while the GC yield presented a decreasing tendency. When the catalyst amount rose to 5\%, a glycerol conversion of $98.8 \%$ and GC yield of $93.2 \%$ were obtained. The decreased GC yield occurred because more glycidol (GD) was generated with the increase of the catalyst amount. This phenomenon could be attributed to the increase in strong basic sites with the rising of the catalyst amount (Song et al. 2017). 
Therefore, the optimum catalyst amount for the transesterification reaction of glycerol with DMC was $3 \%$.

To demonstrate the effect of the reaction time on the transesterification of glycerol with DMC, reactions were completed at different time durations ranging from 60 min to 180 min. Figure $6 \mathrm{c}$ presents the corresponding results. When the reaction time was increased from 60 min to $90 \mathrm{~min}$, the glycerol conversion and GC yield rose from $85.5 \%$ to $98.1 \%$ and $80.3 \%$ to $94.1 \%$, respectively. This result indicated that adequate reaction time allowed for sufficient contact of the reaction mixture with the active alkaline site of the CCR-500 catalyst, leading to high glycerol conversion and GC yield. When the reaction time was longer than $90 \mathrm{~min}$, no obvious increase of the glycerol conversion and GC yield was observed. Thus, 90 min was the suitable reaction time for the transesterification reaction of glycerol with DMC.

Increasing the reaction temperature could improve the miscibility of glycerol with $\mathrm{DMC}$ and allow for better contact between the reagents and the catalyst. Figure $6 \mathrm{~d}$ presents the effect of the reaction temperature on the transesterification reaction of glycerol with DMC. When the reaction temperature was increased from $65{ }^{\circ} \mathrm{C}$ to $80{ }^{\circ} \mathrm{C}$, the glycerol conversion constantly rose from $82.5 \%$ to $98.1 \%$. When the reaction temperature was higher than $80{ }^{\circ} \mathrm{C}$, no obvious increase of the glycerol conversion and GC yield was observed. Moreover, the excessive reaction temperature can lead to the generation of GD (Shikhaliyev et al. 2018). Hence, $80^{\circ} \mathrm{C}$ was the optimum reaction temperature for the transesterification of glycerol with DMC.

\section{Reusability of the CCR-500 catalyst}

Reusability is an important characteristic for heterogeneous catalysts. However, it can be affected by leaching of the active site in the heterogeneous catalysts during the reaction process, which is due to the relatively high reaction temperature and long reaction time (Okoye et al. 2019). To clarify the reusability of the CCR-500 catalyst, a reuse experiment was conducted. After the reaction was finished, the CCR-500 was separated from the reaction mixture and washed three times with ethanol. Then, it was applied in the next cycle after being oven-dried at $150{ }^{\circ} \mathrm{C}$ for $2 \mathrm{~h}$. The result of the reuse experiment is shown in Fig. S1. A gradual decrease of the glycerol conversion and GC yield, from $98.1 \%$ and $94.1 \%$ to $78.2 \%$ and $74.8 \%$, respectively, was observed in the reuse experiment. This observation indicated that the catalytic activity of CCR-500 decreased during the reuse experiment.

Because the decrease of the catalytic activity of a catalyst is usually caused by the leaching of its active site, EDX investigations on the CCR-500 and the reused CCR-500 were performed to explore the reason for the decrease of the catalytic activity of CCR-500. Table 1 shows the corresponding EDX investigation results. After the reuse experiment, the most notable change of the elemental composition of the reused CCR-500 was the evident decrease of the element content of $\mathrm{K}$ and $\mathrm{Cl}$. The content of $\mathrm{K}$ decreased from $10.8 \%$ to $6.1 \%$, and the content of $\mathrm{Cl}$ decreased from $3.4 \%$ to $0 \%$. Because potassium chloride is a neutral salt and the leaching of potassium chloride cannot affect the catalytic activity of CCR500 , an XRD investigation was conducted to clarify the reason behind the decrease in the catalytic activity of CCR-500. 
Table 1. Elemental Composition of the CCR-500 and the Reused CCR-500

\begin{tabular}{|c|c|c|}
\hline Element & CCR-500 (wt\%) & Reused CCR-500 (wt\%) \\
\hline $\mathrm{O}$ & 37.6 & 39.6 \\
\hline $\mathrm{C}$ & 30.1 & 30.7 \\
\hline $\mathrm{K}$ & 10.8 & 6.1 \\
\hline $\mathrm{N}$ & 8.7 & 9.4 \\
\hline $\mathrm{Cl}$ & 3.4 & - \\
\hline $\mathrm{Si}$ & 3.2 & 1.6 \\
\hline $\mathrm{P}$ & 3.1 & 6.1 \\
\hline $\mathrm{Mg}$ & 1.9 & 5.1 \\
\hline $\mathrm{S}$ & 0.7 & 0.9 \\
\hline $\mathrm{Al}$ & 0.5 & 0.5 \\
\hline
\end{tabular}

The XRD investigation result of the CCR-500 and the CCR-500 that was reused four times is presented in Fig. S2. The strong diffraction peaks of potassium chloride were hardly observed in the XRD pattern of the four-times-reused CCR-500, which was in accordance with the EDX investigation results. The decrease of the intensity of the diffraction peak of potassium carbonate was observed simultaneously, which indicated leaching of potassium carbonate contained in the CCR-500 during the reuse experiment. The diffraction peaks of potassium silicate, potassium aluminum pyrophosphate, and potassium magnesium phosphate can still be observed in Fig. S2a, indicating the relatively high stability of these alkaline mineral salts compared to potassium chloride and potassium carbonate. Because potassium carbonate has a relatively high basicity, the leaching of potassium carbonate can lead to the decrease of the catalytic activity in CCR-500.

\section{Comparison of CCR-500 with the reported catalysts}

Usually, a catalyst can be evaluated from two aspects. One is its performance, including its catalytic activity and reusability. The other is the preparation cost of the catalyst. Table 2 shows the comparison of CCR-500 with the reported catalysts from these two aspects. These catalysts were divided into two categories according to the preparation cost, namely: the high-cost catalysts (entries 1 to 4 ) and the low-cost catalysts (entries 5 to 7). The high-cost catalysts were prepared using chemical reagents and the preparation procedure was relatively complicated. Most of the high-cost catalysts showed high catalytic activity with a glycerol conversion higher than $90 \%$ in the transesterification of glycerol with DMC. However, the reusability of the high-cost catalysts was different. The catalyst $\mathrm{KF} / \mathrm{La}-\mathrm{Zr}$ exhibited the lowest reusability. Because of the leaching of KF, the glycerol conversion of the reaction catalyzed by $\mathrm{KF} / \mathrm{La}-\mathrm{Zr}$ decreased to $54 \%$ after it was used 3 times. The catalyst $\mathrm{NiFe}_{2} \mathrm{O}_{4} @\left(\mathrm{CaO}-\mathrm{La}_{2} \mathrm{O}_{3}\right)$ showed the highest reusability among the high-cost catalysts. Even when $\mathrm{NiFe}_{2} \mathrm{O}_{4} @\left(\mathrm{CaO}-\mathrm{La}_{2} \mathrm{O}_{3}\right)$ was used 6 times in the reaction, the glycerol conversion still reached 95\%. Although these high-cost catalysts showed acceptable performance in the reaction, the expensive chemical reagents needed during preparation, and the relatively complicated preparation procedure, hinders the industrial application. The low-cost catalysts were usually prepared by using waste materials. The negligible preparation cost and simple preparation procedure made the low-cost catalysts more attractive in the transesterifcation of glycerol with DMC. As shown in Table 2, the low-cost catalysts exhibited comparably high catalytic activity as the high-cost catalysts. Among these low-cost catalysts, coal fly ash- 
derived catalyst showed the best catalytic activity and reusability (entry 5). However, the preparation of coal fly ash derived catalyst still required a chemical reagent, potassium hydroxide, which made its preparation cost higher than that of the oil palm empty fruit bunch ash (EFBA) and CCR-500. In contrast, the addition of a chemical reagent was not needed to prepare these two waste material-derived catalysts, which meant the preparation cost of the EFBA and CCR-500 was low. Compared with the EFBA, the reusability of CCR-500 was relatively low. After CCR-500 was used 4 times in the reaction, the glycerol conversion only reached $78 \%$. Despite this result, CCR-500 had advantages over the EFBA in terms of the feedstock supply. The feedstock for the EFBA, oil palm empty fruit bunch, can only be obtained in the tropics and subtropics (including Malaysia, Indonesia, west and central Africa, and Central America). Compared with the EFBA, the feedstock for CCR-500, corncob, can be easily collected from plantations all over the world. As the feedstock for the biomass power generation, with the development of the biomass power generation, the collection of corncob residue can be more convenient, leading to appreciably low preparation costs of the corncob residue catalyst. Thus, CCR-500 is a more accessible catalyst than the EFBA and has potential for industrial application in the synthesis of GC by the transesterification of glycerol with DMC.

Table 2. Comparison of the CCR-500 with the Reported Catalysts

\begin{tabular}{|c|c|c|c|c|c|c|}
\hline Entry & Catalyst & Materials ${ }^{a}$ & $\operatorname{Con}_{f}(\%)^{b}$ & $\begin{array}{l}\text { Reuse } \\
\text { Times }\end{array}$ & $\operatorname{Con}_{r}(\%)^{c}$ & Reference \\
\hline 1 & Li/ZnO-500 & $\mathrm{ZnO}, \mathrm{LiNO}_{3}$ & 98 & 4 & 61 & $\begin{array}{c}\text { (Song et al. } \\
\text { 2017) }\end{array}$ \\
\hline 2 & $\mathrm{KF} / \mathrm{La}-\mathrm{Zr}$ & $\begin{array}{c}\mathrm{La}\left(\mathrm{NO}_{3}\right)_{3}, \mathrm{Zr}\left(\mathrm{NO}_{3}\right)_{4} \\
\text { and } \mathrm{KF}\end{array}$ & 92 & 3 & 54 & $\begin{array}{c}\text { (Song et al. } \\
2018)\end{array}$ \\
\hline 3 & Ti-SBA-15 & $\begin{array}{c}\text { Titanium } \\
\text { isopropoxide, SBA- } \\
15\end{array}$ & 94 & 3 & 91 & $\begin{array}{l}\text { (Devi et al. } \\
\text { 2018) }\end{array}$ \\
\hline 4 & $\begin{array}{c}\mathrm{NiFe}_{2} \mathrm{O}_{4} @( \\
\mathrm{CaO}- \\
\left.\mathrm{La}_{2} \mathrm{O}_{3}\right) \\
\end{array}$ & $\begin{array}{l}\mathrm{Ni}\left(\mathrm{NO}_{3}\right)_{2}, \mathrm{Fe}\left(\mathrm{NO}_{3}\right)_{3}, \\
\mathrm{CaCl} \text {, and } \mathrm{La}\left(\mathrm{NO}_{3}\right)_{3}\end{array}$ & 99 & 6 & 95 & $\begin{array}{l}\text { (Zhang et } \\
\text { al. 2018b) }\end{array}$ \\
\hline 5 & K-zeolite & $\mathrm{KOH}$, coal fly ash & 100 & 4 & 94 & $\begin{array}{l}\text { (Algoufi and } \\
\text { Hameed } \\
\text { 2014) }\end{array}$ \\
\hline 6 & Li/zeolite & $\mathrm{LiNO}_{3}$, oil palm ash & 100 & 5 & 86 & $\begin{array}{l}\text { (Khanday et } \\
\text { al. 2017) }\end{array}$ \\
\hline 7 & EFBA & $\begin{array}{c}\text { Oil palm empty fruit } \\
\text { bunch }\end{array}$ & 96 & 4 & 86 & $\begin{array}{l}\text { (Okoye et } \\
\text { al. 2019) }\end{array}$ \\
\hline 8 & CCR-500 & Corncob & 98 & 4 & 78 & $\begin{array}{l}\text { Present } \\
\text { study }\end{array}$ \\
\hline
\end{tabular}

${ }^{a}$ Feedstock for the preparation of the catalyst; ${ }^{b}$ Glycerol conversion corresponding to the fresh catalyst; ${ }^{\mathrm{c}}$ Glycerol conversion corresponding to the reused catalyst

\section{CONCLUSIONS}

1. The corncob residue catalyst prepared by calcination of the corncob at $500{ }^{\circ} \mathrm{C}$ had a relatively high total basicity of $8.8 \mathrm{mmol} / \mathrm{g}$ and showed high catalytic activity in the transesterification reaction of glycerol with DMC. 
2. The structural investigation on CCR-500 indicated that it was composed of carbon material and a certain amount of mineral salts such as potassium chloride, potassium carbonate, potassium silicate. Potassium carbonate and potassium silicate were responsible for the basicity and catalytic activity of CCR-500.

3. The successful application of the corncob residue catalyst in the transesterification reaction of glycerol with DMC can greatly reduce the cost of corncob waste management and promote the utilization of glycerol.

\section{ACKNOWLEDGMENTS}

The authors are grateful for the support from the Open Research Fund of the State Key Laboratory of Polymer Physics and Chemistry, Changchun Institute of Applied Chemistry, Chinese Academy of Sciences (2018-02), the General Project Fund of Liaoning Education Department (LJGD2019014), and the Key Laboratory for Catalyst Synthesis Technology of Polymer of Liaoning Province, China (2010-36). The authors would like to thank Dr. Zhihong Zhang for her contribution to the paper.

\section{REFERENCES CITED}

Algoufi, Y. T., Akpan, U. G., Kabir, G., Asif, M., and Hameed, B. H. (2017). 'Upgrading of glycerol from biodiesel synthesis with dimethyl carbonate on reusable $\mathrm{Sr}-\mathrm{Al}$ mixed oxide catalysts," Energy Conversion and Management 138, 183-189. DOI: 10.1016/j.enconman.2017.01.078

Algoufi, Y. T., and Hameed, B. H. (2014). "Synthesis of glycerol carbonate by transesterification of glycerol with dimethyl carbonate over K-zeolite derived from coal fly ash," Fuel Processing Technology 126, 5-11. DOI: 10.1016/j.fuproc.2014.04.004

Chakraborty, R., Bepari, S., and Banerjee, A. (2010). "Transesterification of soybean oil catalyzed by fly ash and egg shell derived solid catalysts," Chemical Engineering Journal 165(3), 798-805. DOI: 10.1016/j.cej.2010.10.019

Chen, B., Cai, D., Luo, Z., Chen, C., Zhang, C., Qin, P., Cao, H., and Tan, T. (2018). "Corncob residual reinforced polyethylene composites considering the biorefinery process and the enhancement of performance," Journal of Cleaner Production 198, 452-462. DOI: 10.1016/j.jclepro.2018.07.080

Chen, J., Wang, C., Dong, B., Leng, W., Huang, J., Ge, R., and Gao, Y. (2015). “Ionic liquids as eco-friendly catalysts for converting glycerol and urea into high valueadded glycerol carbonate," Chinese Journal of Catalysis 36(3), 336-343. DOI: 10.1016/S1872-2067(14)60257-6

Demiral, I., Eryazici, A., and Şensöz, S. (2012). "Bio-oil production from pyrolysis of corncob (Zea mays L.)," Biomass and Bioenergy 36, 43-49. DOI: 10.1016/j.biombioe.2011.10.045

Devi, P., Das, U., and Dalai, A. K. (2018). "Production of glycerol carbonate using a novel Ti-SBA-15 catalyst," Chemical Engineering Journal 346, 477-488. DOI: https://doi.org/10.1016/j.cej.2018.04.030 
Farnane, M., Tounsadi, H., Machrouhi, A., Elhalil, A., Mahjoubi, F. Z., Sadiq, M., Abdennouri, M., Qourzal, S., and Barka, N. (2018). "Dye removal from aqueous solution by raw maize corncob and $\mathrm{H}_{3} \mathrm{PO}_{4}$ activated maize corncob," Journal of Water Reuse and Desalination 8(2), 214-224. DOI: 10.2166/wrd.2017.179

Gohain, M., Devi, A., and Deka, D. (2017). "Musa balbisiana colla peel as highly effective renewable heterogeneous base catalyst for biodiesel production," Industrial Crops and Products 109, 8-18. DOI: 10.1016/j.indcrop.2017.08.006

Guo, F., Liu, Y., Liu, Y., and Guo, C. (2017). "Catalytic reforming of tar using corncob char and char-supported potassium catalysts," Journal of Thermal Analysis and Calorimetry 130(3), 1297-1306. DOI: 10.1007/s10973-017-6420-3

Gupta, G. K., Ram, M., Bala, R., Kapur, M., and Mondal, M. K. (2018). "Pyrolysis of chemically treated corncob for biochar production and its application in $\mathrm{Cr}(\mathrm{VI})$ removal," Environmental Progress and Sustainable Energy 37(5), 1606-1617. DOI: 10.1002/ep. 12838

Indran, V. P., Haji Saud, A. S., Maniam, G. P., Yusoff, M. M., Taufiq-Yap, Y. H., and Mohd, M. H. (2016). "Versatile boiler ash containing potassium silicate for the synthesis of organic carbonates," RSC Advances, 6(41), 34877-34884. DOI: $10.1039 / \mathrm{c} 5 \mathrm{ra} 26286 \mathrm{k}$

Ioannidou, O., Zabaniotou, A., Antonakou, E. V., Papazisi, K. M., Lappas, A. A., and Athanassiou, C. (2009). "Investigating the potential for energy, fuel, materials and chemicals production from corn residues (cobs and stalks) by non-catalytic and catalytic pyrolysis in two reactor configurations," Renewable and Sustainable Energy Reviews 13(4), 750-762. DOI: 10.1016/j.rser.2008.01.004

Jung, J. M., Lee, S. R., Lee, J., Lee, T., Tsang, D. C. W., and Kwon, E. E. (2017). "Biodiesel synthesis using chicken manure biochar and waste cooking oil," Bioresource Technology 244, 810-815. DOI: 10.1016/j.biortech.2017.08.044

Khanday, W. A., Okoye, P. U., and Hameed, B. H. (2017). "Biodiesel byproduct glycerol upgrading to glycerol carbonate over lithium-oil palm ash zeolite," Energy Conversion and Management 151, 472-480. DOI:

10.1016/J.ENCONMAN.2017.08.091

Kleingesinds, E. K., José, Á. H. M., Brumano, L. P., Silva-Fernandes, T., Rodrigues, D., and Rodrigues, R. C. L. B. (2018). "Intensification of bioethanol production by using Tween 80 to enhance dilute acid pretreatment and enzymatic saccharification of corncob," Industrial Crops and Products 124, 166-176. DOI: 10.1016/j.indcrop.2018.07.037

Li, M., Zhang, H., Xiao, T., Wang, S., Zhang, B., Chen, D., Su, M., and Tang, J. (2018a). "Low-cost biochar derived from corncob as oxygen reduction catalyst in air cathode microbial fuel cells," Electrochimica Acta 283, 780-788. DOI:

10.1016/j.electacta.2018.07.010

Li, X. F., Zuo, Y., Zhang, Y., Fu, Y., and Guo, Q. X. (2013). "In situ preparation of $\mathrm{K}_{2} \mathrm{CO}_{3}$ supported kraft lignin activated carbon as solid base catalyst for biodiesel production," Fuel 113, 435-442. DOI: 10.1016/j.fuel.2013.06.008

Li, X., Yang, L., Gu, X., Lai, C., Huang, C., and Yong, Q. (2018b). “A combined process for production of fumaric acid and xylooligosaccharides from corncob," BioResources 13(1), 399-411. DOI: 10.15376/biores.13.1.399-411

Manaf, I. S. A., Rahim, M. H. A., Govindan, N., and Maniam, G. P. (2018). “A first report on biodiesel production from Aglaia korthalsii seed oil using waste marine barnacle as 
a solid catalyst," Industrial Crops and Products 125, 395-400. DOI:

10.1016/j.indcrop.2018.09.022

Nguyen-Phu, H., Park, C. yi, and Shin, E. W. (2018). "Dual catalysis over ZnAl mixed oxides in the glycerolysis of urea: Homogeneous and heterogeneous reaction routes," Applied Catalysis A: General 552, 1-10. DOI: 10.1016/j.apcata.2017.12.018

Okoye, P. U., Abdullah, A. Z., and Hameed, B. H. (2016). "Glycerol carbonate synthesis from glycerol and dimethyl carbonate using trisodium phosphate," Journal of the Taiwan Institute of Chemical Engineers 68, 51-58. DOI: 10.1016/j.jtice.2016.09.011

Okoye, P. U., Wang, S., Xu, L., Li, S., Wang, J., and Zhang, L. (2019). "Promotional effect of calcination temperature on structural evolution, basicity, and activity of oil palm empty fruit bunch derived catalyst for glycerol carbonate synthesis," Energy Conversion and Management 179, 192-200. DOI: 10.1016/j.enconman.2018.10.013

Qu, W. H., Xu, Y. Y., Lu, A. H., Zhang, X. Q., and Li, W. C. (2015). “Converting biowaste corncob residue into high value added porous carbon for supercapacitor electrodes," Bioresource Technology 189, 285-291. DOI: 10.1016/j.biortech.2015.04.005

Sani, Y. M., Raji, A. O., Alaba, P. A., Abdul Aziz, A. R., and Wan Daud, W. M. A. (2015). "Palm frond and spikelet as environmentally benign alternative solid acid catalysts for biodiesel production," BioResources 10(2), 3393-3408. DOI:

10.15376/biores.10.2.3393-3408

Shikhaliyev, K., Okoye, P. U., and Hameed, B. H. (2018). "Transesterification of biodiesel byproduct glycerol and dimethyl carbonate over porous biochar derived from pyrolysis of fishery waste," Energy Conversion and Management 165, 794-800. DOI: 10.1016/j.enconman.2018.04.001

Song, X., Pan, D., Wu, Y., Cheng, P., Wei, R., Gao, L., Zhang, J., and Xiao, G. (2018). "Synthesis of glycerol carbonate over porous La-Zr based catalysts: The role of strong and super basic sites," Journal of Alloys and Compounds 750, 828-837. DOI: 10.1016/j.jallcom.2018.03.392

Song, X., Wu, Y., Cai, F., Pan, D., and Xiao, G. (2017). "High-efficiency and low-cost $\mathrm{Li} / \mathrm{ZnO}$ catalysts for synthesis of glycerol carbonate from glycerol transesterification: The role of Li and ZnO interaction," Applied Catalysis A: General 532, 77-85. DOI: 10.1016/j.apcata.2016.12.019

Wang, S., Hao, P., Li, S., Zhang, A., Guan, Y., and Zhang, L. (2017). "Synthesis of glycerol carbonate from glycerol and dimethyl carbonate catalyzed by calcined silicates," Applied Catalysis A: General 542, 174-181. DOI:

10.1016/j.apcata.2017.05.021

Wang, S., Wang, J., Sun, P., Xu, L., Okoye, P. U., Li, S., Zhang, L., Guo, A., Zhang, J., and Zhang, A. (2019). "Disposable baby diapers waste derived catalyst for synthesizing glycerol carbonate by the transesterification of glycerol with dimethyl carbonate," Journal of Cleaner Production, 211, 330-341. DOI:

10.1016/j.jclepro.2018.11.196

Wang, S., Xu, L., Okoye, P. U., Li, S., and Tian, C. (2018). "Microwave-assisted transesterification of glycerol with dimethyl carbonate over sodium silicate catalyst in the sealed reaction system," Energy Conversion and Management 164, 543-551. DOI: 10.1016/j.enconman.2018.03.021

You, T., Li, X., Wang, R., Zhang, X., and Xu, F. (2019). "Effects of synergistic fungal pretreatment on structure and thermal properties of lignin from corncob," Bioresource Technology 272, 123-129. DOI: 10.1016/j.biortech.2018.09.145 
Zhang, L., Li, S., Li, K., and Zhu, X. (2018a). "Two-step pyrolysis of corncob for valueadded chemicals and high quality bio-oil: Effects of pyrolysis temperature and residence time," Energy Conversion and Management 166, 260-267. DOI:

10.1016/j.enconman.2018.04.002

Zhang, P., Zhu, M., Fan, M., Jiang, P., and Dong, Y. (2018b). "Rare earth-doped calciumbased magnetic catalysts for transesterification of glycerol to glycerol carbonate," Journal of the Chinese Chemical Society 66(2), 164-170. DOI: 10.1002/jccs. 201800164

Zheng, L., Peng, D., and Meng, P. (2019). "Corncob-supported aluminium-manganese binary oxide composite enhanced removal of cadmium ions," Colloids and Surfaces A: Physicochemical and Engineering Aspects 561, 109-119. DOI: 10.1016/j.colsurfa.2018.10.075

Zhu, J., Li, Y., Xu, L., and Liu, Z. (2018). "Removal of toluene from waste gas by adsorption-desorption process using corncob-based activated carbons as adsorbents," Ecotoxicology and Environmental Safety 165(135), 115-125. DOI:

10.1016/j.ecoenv.2018.08.105

Article submitted: June 4, 2019; Peer review completed: August 15, 2019; Revised version accepted: November 7, 2019; Published: November 11, 2019.

DOI: $10.15376 /$ biores.15.1.142-158 


\section{APPENDIX: SUPPLEMENTARY MATERIAL}

Table S1. Textural Properties of Corncob, CCR-500, and the reused CCR-500

\begin{tabular}{|c|c|c|c|}
\hline Material & $\begin{array}{c}\text { BET Surface Area } \\
\left(\mathrm{m}^{2} \mathrm{~g}^{-1}\right)\end{array}$ & Pore Diameter $(\mathrm{nm})$ & Pore Volume $\left(\mathrm{cm}^{3} \mathrm{~g}^{-1}\right)$ \\
\hline corncob & 2.54 & 26.86 & 0.017 \\
\hline CCR-500 & 3.08 & 19.87 & 0.015 \\
\hline $\begin{array}{c}4 \text { times reused } \\
\text { CCR-500 }\end{array}$ & 2.91 & 20.28 & 0.014 \\
\hline
\end{tabular}

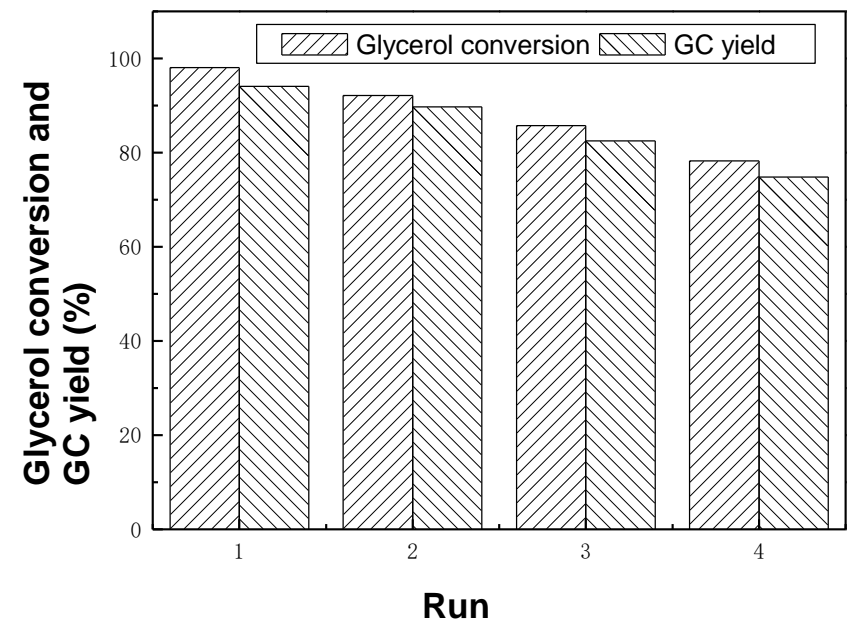

Fig. S1. Reusability of the CCR-500 (reaction conditions: glycerol: $0.05 \mathrm{~mol}(4.6 \mathrm{~g}$ ), DMC: $0.15 \mathrm{~mol}$ (13.5 g), catalyst amount: $3 \mathrm{wt} \%(0.54 \mathrm{~g})$, temperature: $80^{\circ} \mathrm{C}$, and time: $\left.90 \mathrm{~min}\right)$

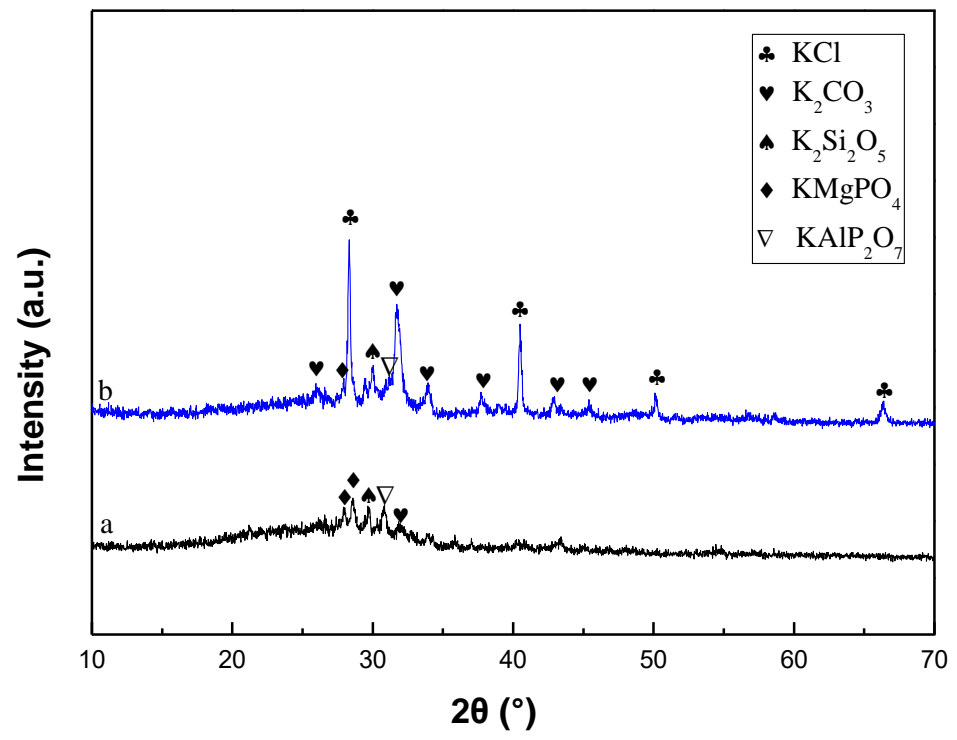

Fig. S2. XRD patterns of (a) the four times reused CCR-500 and (b) the CCR-500 